University of Wollongong

Research Online

Faculty of Engineering and Information

Faculty of Engineering and Information

Sciences - Papers: Part B

Sciences

2020

\title{
An Integrated Energy Management Approach for the Economic Operation of Industrial Microgrids under Uncertainty of Renewable Energy
}

Ghulam Mohy-ud-din

University of Wollongong, gmud774@uowmail.edu.au

Dao Hoang Vu

dhv972@uowmail.edu.au

Kashem M. Muttaqi

University of Wollongong, kashem@uow.edu.au

Danny Sutanto

University of Wollongong, soetanto@uow.edu.au

Follow this and additional works at: https://ro.uow.edu.au/eispapers1

Part of the Engineering Commons, and the Science and Technology Studies Commons

Research Online is the open access institutional repository for the University of Wollongong. For further information contact the UOW Library: research-pubs@uow.edu.au 


\title{
An Integrated Energy Management Approach for the Economic Operation of Industrial Microgrids under Uncertainty of Renewable Energy
}

\author{
Abstract \\ (C) 1972-2012 IEEE. Many modern industries are equipped with onsite renewable generation and are \\ normally connected to the grid. A battery energy storage system (BESS) can complement the \\ intermittency of the available onsite renewable generation. The combination of the BESS and the \\ renewable generation can operate as a microgrid. If the microgrid is properly sized and managed, it is \\ possible to reduce the electricity bill to have a huge saving in the electricity cost. This article proposes an \\ energy management system for such an industrial microgrids. The decisions to charge and discharge the \\ BESS in the proposed energy management are usually constrained by the size of the energy storage. The \\ proposed energy management strategy aims to optimize the operation of the industrial microgrids \\ subject to the scalability of the BESS under uncertainties. The proposed optimization involves two stages. \\ In the first stage of optimization, it determines the optimum size of the energy storage taking into account \\ the cost of the BESS, and in the second stage, it minimizes the cost of the microgrid operation based on \\ the decision made in the first stage. This proposed two-stage energy management strategy is formulated \\ as a single-stage linear program that incorporates stochastic scenarios for addressing uncertainties. In \\ addition, the proposed strategy also considers the various operating limits of the energy storage, such as \\ the efficiency and the charging and the discharging rates, and considers the fading effect of the batteries \\ of the BESS. The proposed strategy is then validated using two typical datasets from two different \\ industrial units in New South Wales, Australia. The simulation results show that the proposed strategy \\ effectively calculates the optimum size of the BESS and reduces the operational cost.

\section{Disciplines} \\ Engineering | Science and Technology Studies

\section{Publication Details} \\ G. Mohy-ud-din, D. Vu, K. Muttaqi \& D. Soetanto, "An Integrated Energy Management Approach for the \\ Economic Operation of Industrial Microgrids under Uncertainty of Renewable Energy," IEEE Transactions \\ on Industry Applications, vol. 56, (2) pp. 1062-1073, 2020.
}




\title{
An Integrated Energy Management Approach for the Economic Operation of Industrial Microgrids under Uncertainty of Renewable Energy
}

\author{
G. Mohy-ud-din, Student member, IEEE, D. H. Vu, K. M. Muttaqi, Senior Member, IEEE, and D. \\ Sutanto, Senior Member, IEEE
}

\begin{abstract}
Many modern industries are equipped with on-site renewable generation and are normally connected to the grid. A battery energy storage system (BESS) can complement the intermittency of the available on-site renewable generation. The combination of the BESS and the renewable generation can operate as a microgrid. If the microgrid is properly sized and managed, it is possible to reduce the electricity bill to have a huge saving in the electricity cost. This paper proposes an energy management system for such an industrial microgrids. The decisions to charge and discharge the BESS in the proposed energy management are usually constrained by the size of the energy storage. The proposed energy management strategy aims to optimize the operation of the industrial microgrids subject to the scalability of the BESS under uncertainties. The proposed optimization involves two stages. In the first stage of optimization, it determines the optimum size of the energy storage taking into account the cost of the BESS, and in the second stage, it minimizes the cost of the microgrid operation based on the decision made in the first stage. This proposed two-stage energy management strategy is formulated as a single stage linear program that incorporates stochastic scenarios for addressing uncertainties. In addition, the proposed strategy also considers the various operating limits of the energy storage such as the efficiency, the charging and the discharging rates and considers the fading effect of the batteries of the BESS. The proposed strategy is then validated using two typical data sets from two different industrial units in New South Wales, Australia. The simulation results show that the proposed strategy effectively calculates the optimum size of the BESS and reduces the operational cost.
\end{abstract}

Index Terms-Industrial Microgrids, Battery Energy Storage, Integrated energy management, Renewable Energy Uncertainty.
A. Indices
$i \quad$ Time steps indices.
$k \quad$ Scenario indices.
B. Parameters
$p_{\text {in }} \quad$ Investment cost of energy storage (in $\$ / \mathrm{kWh}$ ).
$\widetilde{\pi}_{\mathrm{i}}^{\mathrm{B}} \quad$ Expected price for buying energy at hour $i$ (in $\$ / \mathrm{kWh}$ ).
$\widetilde{\pi}_{\mathrm{i}}^{\mathrm{S}} \quad$ Expected price for selling energy at hour $i$ (in $\$ / \mathrm{kWh}$ ).
$E_{p} \quad$ Maximum possible value of energy storage (in $\mathrm{kWh}$ ).
$\mathrm{P}_{\max }^{\mathrm{BC}} \quad$ Maximum BESS charging power limit (in $\mathrm{kW} / \mathrm{h}$ ).
$\mathrm{P}_{\max }^{\mathrm{BD}} \quad$ Maximum BESS discharging power limit (in $\mathrm{kW} / \mathrm{h}$ ).
$\widetilde{\mathrm{P}}_{\mathrm{i}, \mathrm{max}}^{\mathrm{BC}} \quad$ Maximum charging power limit at hour $i$ (in $\mathrm{kW} / \mathrm{h}$ ).
$\widetilde{\mathrm{P}}_{\mathrm{i}, \mathrm{BD}}^{\mathrm{BD}} \quad$ Maximum discharging power limit at hour $i($ in $\mathrm{kW} / \mathrm{h})$.
$\widetilde{\mathrm{P}}_{\mathrm{i}}^{\mathrm{Ld}} \quad$ Expected load demand of microgrid at hour $i$ (in $\mathrm{kW}$ ).
$\widetilde{\mathrm{P}}_{\mathrm{i}}^{\mathrm{DG}} \quad$ Expected generated power of DG at hour $i$ (in $\mathrm{kW}$ ).

$E_{0} \quad$ Initial value of charge in energy storage (in $\mathrm{kWh}$ ).

$\eta_{C, i} \quad$ Efficiency losses during charging at hour $i$ (in \%).

$\eta_{D, i} \quad$ Efficiency losses during discharging at hour $i$ (in \%).

$\gamma_{\mathrm{k}} \quad$ Probability of scenario $k$.

$\mathrm{K} \quad$ Total number of scenarios.

$\mathrm{T}$ Total number of time steps in the simulation.

$\pi_{\mathrm{k}, \mathrm{i}}^{\mathrm{B}} \quad$ Buying energy price in scenario $k$ at hour $i$ (in $\$ / \mathrm{kWh}$ ).

$\pi_{\mathrm{k}, \mathrm{i}}^{\mathrm{S}} \quad$ Selling energy price in scenario $k$ at hour $i$ (in $\$ / \mathrm{kWh}$ ).

$\mathrm{P}_{\mathrm{k}, \mathrm{i}}^{\mathrm{Ld}} \quad$ Microgrid load demand in scenario $k$ at hour $i$ (in $\mathrm{kW}$ ).

$\mathrm{P}_{\mathrm{k}, \mathrm{i}}^{\mathrm{DG}} \quad$ DG generated power in scenario $k$ at hour $i$ (in $\mathrm{kW}$ ).

$\mathrm{P}_{\mathrm{k}, \mathrm{i}, \mathrm{max}}^{\mathrm{BC}}$ Max. charging power in scenario $k$ at hour $i$ (in $\mathrm{kW} / \mathrm{h}$ ).

$\mathrm{P}_{\mathrm{k}, \mathrm{i} \text {,max }}^{\mathrm{BD}}$ Max. discharge-power in scenario $k$ at hour $i$ (in $\mathrm{kW} / \mathrm{h}$ ).

$u_{\mathrm{k}, \mathrm{i}}^{B C} \quad$ Auxiliary variable in scenario $k$ at hour $i$ for charging.

$u_{\mathrm{k}, \mathrm{i}}^{B D} \quad$ Auxiliary variable in scenario $k$ at hour $i$ for discharge.

$\eta_{C, k, i} \quad$ Charging efficiency in scenario $k$ at hour $i$ (in $\%$ ).

$\eta_{D, k, i} \quad$ Discharging efficiency in scenario $k$ at hour $i$ (in \%).

C. Decision Variables

$\mathrm{E}_{\max } \quad$ Maximum capacity of the energy storage (in $\mathrm{kWh}$ ).

$\widetilde{\mathrm{P}}_{\mathrm{i}}^{\mathrm{B}} \quad$ Expected power bought in scenario $k$ at hour $i$ (in $\mathrm{kW}$ ).

$\widetilde{\mathrm{P}}_{\mathrm{i}}^{\mathrm{S}} \quad$ Expected power sold in scenario $k$ at hour $i$ (in $\mathrm{kW}$ ).

$\widetilde{\mathrm{P}}_{\mathrm{i}}^{\mathrm{BC}} \quad$ Expected charging power at hour $i$ (in $\mathrm{kW}$ ).

$\widetilde{\mathrm{P}}_{\mathrm{i}}^{\mathrm{BD}} \quad$ Expected discharging power at hour $i$ (in $\mathrm{kW}$ ).

$E_{\mathrm{i}} \quad$ Energy level of the energy storage at hour $i$ (in $\mathrm{kWh}$ ).

$\mathrm{P}_{\mathrm{k}, \mathrm{i}}^{\mathrm{B}} \quad$ Power bought in scenario $k$ at hour $i$ (in $\mathrm{kW}$ ).

$\mathrm{P}_{\mathrm{k}, \mathrm{i}}^{\mathrm{S}} \quad$ Power sold in scenario $k$ at hour $i$ (in $\mathrm{kW}$ ).

$\mathrm{P}_{\mathrm{k}, \mathrm{i}}^{\mathrm{BC}} \quad$ Charging power in scenario $k$ at hour $i$ (in $\mathrm{kW}$ ).

$\mathrm{P}_{\mathrm{k}, \mathrm{i}}^{\mathrm{BD}} \quad$ Discharging power in scenario $k$ at hour $i$ (in $\mathrm{kW}$ ).

$E_{\mathrm{k}, \mathrm{i}} \quad$ Energy level of storage in scenario $k$ at hour $i$ (in $\mathrm{kWh}$ ).

\section{INTRODUCTION}

W ITH the increasing penetration of the uncertain renewable energy generation, such as wind and solar, a reliable energy storage solution becomes a necessity. Specially, the BESSs are evolving as an efficient source of flexibility and resilience to the power grids [1]. The industrial community seeking for the on-site and less expensive renewable energy generation in form of a small scale centralized, reliable and selfregulated microgrid cannot sustain without integrated BESSs [2]. Moreover, with the advent of bidirectional technologies, the microgrid operators can exploit the dynamic market prices by storing the energy during off-peak, low-price periods for use in the peak-price periods [3], [4]. However, the investment cost

This work is supported by Higher Education Commission Pakistan and University of Wollongong Australia research scholarship program.

D. H. Vu is with the Aurecon, Sydney, Australia. G. Mohy-ud-din, K. M. Muttaqi and D. Sutanto are with the Australian Power Quality and Reliability Centre, School of Electrical, Computer and Telecommunications Engineering, University of Wollongong, Wollongong, New South Wales, 2522, Australia. (e-mails: gmud774@uowmail.edu.au; dhv972@uowmail.edu.au; kashem@uow.edu.au; soetanto@uow.edu.au). 
for the BESSs is high [5]. Therefore, the dynamics and the scalability of the BESS, uncertain renewable energy, unpredictable load demand and highly volatile market price makes the energy management of an industrial microgrid a real challenge.

The reported literature on the optimal demand-side energy management with BESSs is diverse in objectives and developing rapidly. Most dominant models are the demand response strategies for the consumers [6], [7]. However, such strategies exhibit only minor load shifts to regulate the prices. Earlier energy management strategies employ deterministic optimization (DO) techniques to reduce finite horizon energy costs with a presumption that the prices are known in advance without considering the uncertain parameters involved in the decision-making process [8], [9]. Another set of studies present Markov decision process (MDP) model-based energy management approach with fixed storage capacity. It results in a dual threshold for cost minimizing energy storage policy [10]. Moreover, in [11], a simple threshold policy is developed to mitigate the intermittency of the solar energy with integrated BESS that improves the frequency response and voltage control of the network. In addition, in [12], an optimal BESS control with price and generation uncertainty is presented. This strategy uses an infinite horizon MDP model, where an optimal threshold policy is derived for online solution and it is proved to be asymptotically optimal (when BESS capacity reaches infinity). However, the major problem of MDPs is to find a policy for decision making under situations when the outcomes are partially random and partially in control. Moreover, none of these methods considers simultaneous uncertain parameters such as generation, demand and the energy price.

Robust optimization (RO) is another broad category of techniques applied for addressing the uncertainties involved in the energy management process of microgrids. In RO, predefined uncertainty margins for the intermittent variables are used to stay at the safer side during real-time operation. In [13], a multi-objective RO is used for the energy management of multi-microgrid industrial park, where the collective profit of microgrids is maximized, while protecting the system against any unforeseen disturbance in the forecast of uncertain parameters. In [14], an adaptive RO approach is used for the energy management of industrial multi-energy micro-grids in different timescales. In [15], a day-ahead planning of unbalanced microgrids is studied using two-stage robust optimization considering the day-ahead and real-time energy market stages. In [16], an energy management based on RO reduces operation cost for operating all the electrical and thermal appliances, BESSs, and electric vehicles (EVs). In [17], another variant of RO, distributionally robust chanceconstrained optimization is applied for energy management of islanded microgrids. Here, the uncertainty sets are defined using probability distributions. In [18], the uncertainty sets are defined by using the historical data without imposing any specific probability distribution, which makes this approach more realistic in comparison to the chance-constrained RO. However, all of these RO techniques produce conservative solutions with considerable curtailment of the available renewable energy.
Heuristic optimization ( $\mathrm{HO}$ ) techniques are also widely utilized for the energy management of microgrids [19], [20]. However, in the presence of uncertain parameters these iterative optimization techniques have large computational times. To avoid such computational barriers, heuristic BESS optimization models [21] split the BEES scalability into a sequential decision framework in accordance with the heuristic rules. Although, the heuristic optimization models are solvable for longer time horizons, but they often converge onto sub-optimal solutions.

Recently, the model predictive control (MPC) method has been employed for the energy management of microgrids. It uses a receding horizon control method applied on an explicit model to predict the optimal operation set points for the microgrid resources under real-time disturbances (forecast errors). In [22], the MPC is used for the minimization of the operational cost of the microgrids. In [23], a distributed MPC is used to effectively minimize the operational costs of microgrids in the day-ahead and peer-to-peer operation modes. In [24], a hierarchical distributed MPC is implemented to solve the energy management problem with the multi-time frame and multi-layer optimization strategy for the microgrids. However, MPC requires a predefined model for the system, which is formulated as a linear model to avoid computational complexity that may result in non-optimal solutions. Moreover, it suffers from a significant computational burden solving a longer prediction horizon. Furthermore, this approach is based on a single scenario optimization.

Consequently, the stochastic programming (SP) has emerged as a suitable alternative to the DO, MDP, RO, HO and MPC models for energy management problems with continuous actions and high dimensionality [25]. The SP based optimization framework utilizes higher number of stochastic scenarios for modelling the uncertain parameters. The stochastic optimization has been extensively employed in the microgrid energy management frameworks [26], [27]. In [27], a two-stage linear SP framework is modelled to minimize the investment and ancillary generation costs in a network having higher penetration of renewables and energy storage. A wellknown L-shaped algorithm is employed to solve for the dayahead operation of microgrid, however, with a relatively small number of scenarios. In [28], a two-stage stochastic, mixedinteger, quadratic programming based framework is formulated to jointly optimize the day-ahead operation of renewables and BESS in a microgrid, using a small number of scenarios. In [29], a co-optimized real-time scheduling of BESS for energy and regulation services is performed by considering price and renewable generation uncertainty. The problem is formulated as a two-stage, stochastic mixed-integer program to obtain a piecewise linear function approximation of MDP model with continuous states and actions. Similar use of the SP models can be seen in [30]-[32]. In general, most of the real SP frameworks are NP-hard (non-deterministic polynomial-time hardness), however, their predominance in the literature stems from their efficient use in several decomposition algorithms [33]. In comparison, multi-stage SP models that use complex algorithms for computation are lesser in the literature, because they return the solutions that are non-anticipative (decision taken in a stage depends only on the relevant information up to 
that stage), although, they are difficult to solve and are tractable only up to limited stages [34]. In contrast, the two-stage models are anticipative and more tractable.

Furthermore, all of these energy management approaches considers the BESS dynamics with some inaccuracy by considering constant charging and discharging efficiency parameters, however, these parameters are a function of charging and discharging power, which are considered in this paper. Moreover, compared to an earlier version of this work in [35], in this paper, a more generalized solution approach with extensive case studies is presented for the energy management of an industrial microgrid.

The major contributions of this paper can be summarized as follows:

- This paper proposes a novel, two-stage SP model to obtain optimal procurement and operation strategies for a BESS in a grid-connected industrial microgrid. The first stage is the decision of the BESS capacity subject to the budget under investment cost. During the subsequent stage of the planning horizon, recourse decisions are made, that includes the power procured from or supplied to the grid and the power charged to or discharged from the BESS. The objective is the minimization of the total expected energy cost over a finite planning horizon, subject to the BESS capacity and the physical constraints. The distinguishing feature of the proposed model is that the decisions are made by simultaneously considering multiple sources of uncertainty such as renewables, load and prices. Furthermore, to overcome the computation challenge the two-stage SP is formulated as a single stage linear program (LP) for efficient solution.

- A novel and more accurate model of the BESS is used in this paper. Unlike the traditional BESS models presented in the literature, using a fixed charging and discharging power limit and constant efficiencies (losses), this paper derives the efficiency parameters as a linear function of the charging and discharging power values and the charging and discharging power as a function of price to utilize the valuable resource more effectively. Furthermore, the fading effect of the BESSs is also considered as a function of charging-discharging cycles to ensure a more accurate calculation of BESS capacity.

- The proposed approach is not only applicable to the typical positive price profile but the price profiles with negative price peaks as well.

- The proposed approach has been successfully evaluated through numerical studies based on real data.

The simulation studies are performed on two distinctive data sets acquired from two different industrial companies in NSW, Australia connected to an electricity distribution network in New South Wales (NSW), Australia. The results show the effectiveness of the proposed energy management strategy in terms of the reduction in the operational cost of the microgrid.

The rest of the paper is organized as follows: Section II presents the problem formulation in detail. Section III discusses the outcomes of the proposed approach on the numerical studies. Section IV provides the concluding remarks followed by the references.

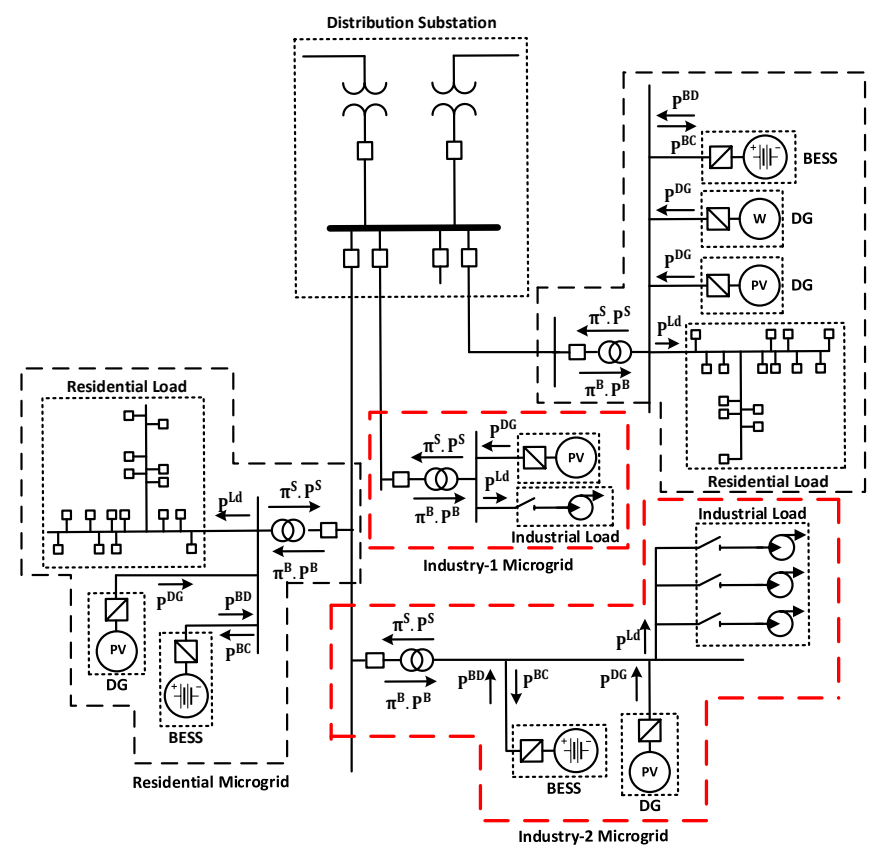

Fig. 1. A typical distribution network with DERs operating as microgrids

\section{The Proposed ENERgy MANAGEMENT StRATEgY}

\section{A. Optimization Model}

In a typical distribution network, the industrial microgrids interact with the main grid as shown in Fig. 1. The power flow between the microgrids and the main grid is bi-directional and the profit of the microgrid operator solely depends on the trading prices. The main objective of the proposed energy management strategy is to minimize the operational cost of the microgrid using scalable energy storage. In such scenario, the cost of a microgrid is typically estimated in two main parts: the investment cost and the operational cost. An energy storage can create a significant reduction in the microgrid operational cost by maximizing the profit earned by the microgrid. Thus, in this study, to minimize the overall cost of the microgrid subject to the system constraints, the objective function and the constraints are formulated as follows:

$$
\begin{gathered}
\text { Min } p_{i n} \cdot \mathrm{E}_{\max }+\mathbb{E}\left(\sum_{\mathrm{i}=1}^{T}\left(\widetilde{\pi}_{\mathrm{i}}^{\mathrm{B}} \cdot \widetilde{\mathrm{P}}_{\mathrm{i}}^{\mathrm{B}}-\widetilde{\pi}_{\mathrm{i}}^{\mathrm{S}} \cdot \widetilde{\mathrm{P}}_{\mathrm{i}}^{\mathrm{S}}+\mathcal{P} \tilde{\mathrm{d}}_{\mathrm{i}}\right)\right) \\
0 \leq \mathrm{E}_{\max } \leq E_{p} \\
\left(\widetilde{\mathrm{P}}_{\mathrm{i}}^{\mathrm{B}}-\widetilde{\mathrm{P}}_{\mathrm{i}}^{\mathrm{S}}\right)+\left(\widetilde{\mathrm{P}}_{\mathrm{i}}^{\mathrm{BC}}-\widetilde{\mathrm{P}}_{\mathrm{i}}^{\mathrm{BD}}\right)=\left(\widetilde{\mathrm{P}}_{\mathrm{i}}^{\mathrm{Ld}}-\widetilde{\mathrm{P}}_{\mathrm{i}}^{\mathrm{DG}}\right) \\
0 \leq \widetilde{\mathrm{P}}_{\mathrm{i}}^{\mathrm{BD}} \leq \min \left(\widetilde{\mathrm{P}}_{\mathrm{i}, \max }^{\mathrm{BD}}, \mathrm{P}_{\max }^{\mathrm{BD}}\right) \\
0 \leq \widetilde{\mathrm{P}}_{\mathrm{i}}^{\mathrm{BC}} \leq \min \left(\widetilde{\mathrm{P}}_{\mathrm{i}, \max }^{\mathrm{BC}}, \mathrm{P}_{\max }^{\mathrm{BC}}\right) \\
E_{\mathrm{i}}=E_{\mathrm{k}, i-1}+\eta_{C, i} \widetilde{\mathrm{P}}_{\mathrm{i}}^{\mathrm{BC}}-\frac{\widetilde{\mathrm{P}}_{\mathrm{i}}^{\mathrm{BD}}}{\eta_{D, i}} \\
E_{\min } \leq E_{\mathrm{i}} \leq E_{\max }
\end{gathered}
$$

where, the first element $p_{i n}$. $\mathrm{E}_{\max }$ represents the investment cost. In this case, the investment cost is linearly related to the capacity of the installed battery storage. The second part of the objective function $\mathbb{E}\left(\sum_{\mathrm{i}=1}^{24}\left(\widetilde{\pi}_{\mathrm{i}}^{\mathrm{B}} \cdot \widetilde{\mathrm{P}}_{\mathrm{i}}^{\mathrm{B}}-\widetilde{\pi}_{\mathrm{i}}^{\mathrm{S}} \cdot \widetilde{\mathrm{P}}_{\mathrm{i}}^{\mathrm{S}}+\mathcal{P} \tilde{\mathrm{d}}_{\mathrm{i}}\right)\right)$ represents the expected operational cost of the microgrid. Note that, at the time of solving (1), $\widetilde{\pi}_{i}^{B}, \widetilde{\mathrm{P}}_{\mathrm{i}}^{\mathrm{B}}, \widetilde{\pi}_{\mathrm{i}}^{\mathrm{S}}, \widetilde{\mathrm{P}}_{\mathrm{i}}^{\mathrm{S}}, \widetilde{\mathrm{P}}_{\mathrm{i}}^{\mathrm{BC}}, \widetilde{\mathrm{P}}_{\mathrm{i}}^{\mathrm{BD}}, \widetilde{\mathrm{P}}_{\mathrm{i}}^{\mathrm{Ld}}, \widetilde{\mathrm{P}}_{\mathrm{i}}^{\mathrm{DG}}, \tilde{\mathrm{d}}_{\mathrm{i}}$, $\widetilde{\mathrm{P}}_{\mathrm{i}, \max }^{\mathrm{BD}}$ and $\widetilde{\mathrm{P}}_{\mathrm{i}, \text { max }}^{\mathrm{BC}}$ are unknown stochastic parameters. Moreover, 
to avoid high peak demand charges from the grid, the power bought from the grid is constrained with a penalty rate $\mathcal{P}$, if it exceeds a certain threshold $T$. Such that $\tilde{d}_{i}=\max \left(0, \widetilde{\mathrm{P}}_{i}^{B}-\mathrm{T}\right)$, which means if the exceeded amount of power is positive, penalty is applied and when it is negative, no charges are applied. Also, for every scenario $k$, if $i=1$ and $T, E_{\mathrm{k}, i-1}=E_{0}$.

By the definition of expectation in mathematics, we can rewrite the second term of the objective function in (1) as a weighted summation of the microgrid cost term, a large but finite number of scenarios, where the weight represents the probability of each scenario. That is:

$$
\begin{aligned}
\mathbb{E}\left(\sum_{\mathrm{i}=1}^{24}\left(\widetilde{\pi}_{\mathrm{i}}^{\mathrm{B}} \cdot \widetilde{\mathrm{P}}_{\mathrm{i}}^{\mathrm{B}}-\widetilde{\pi}_{\mathrm{i}}^{\mathrm{S}} \cdot \widetilde{\mathrm{P}}_{\mathrm{i}}^{\mathrm{S}}\right)\right) \\
=\sum_{\mathrm{k}=1}^{\mathrm{K}} \gamma_{\mathrm{k}} \sum_{\mathrm{i}=1}^{T}\left(\pi_{\mathrm{k}, \mathrm{i}}^{\mathrm{B}} \cdot \mathrm{P}_{\mathrm{k}, \mathrm{i}}^{\mathrm{B}}-\pi_{\mathrm{k}, \mathrm{i}}^{\mathrm{S}} \cdot \mathrm{P}_{\mathrm{k}, \mathrm{i}}^{\mathrm{S}}+\mathcal{P} \mathrm{d}_{\mathrm{k}, \mathrm{i}}\right)
\end{aligned}
$$

where $\sum_{\mathrm{k}=1}^{\mathrm{K}} \gamma_{\mathrm{k}}=1$. It is worth mentioning that the main cause of uncertainty is the varying renewable based DG power prices and the load demands. Therefore, in this model, each scenario is derived as a realization of the available DG power, locational marginal price and the load demand, given the probability distribution functions, that are assumed to be available, e.g., by the use of the forecasting techniques. Thus, for each scenario $k$, the corresponding aggregate operation cost of the microgrid, while satisfying the given constraints can be calculated as follows:

$$
\begin{gathered}
\text { Min } \sum_{\mathrm{k}=1}^{\mathrm{K}} \gamma_{\mathrm{k}} \sum_{\mathrm{i}=1}^{T}\left(\pi_{\mathrm{k}, \mathrm{i}}^{\mathrm{B}} \cdot \mathrm{P}_{\mathrm{k}, \mathrm{i}}^{\mathrm{B}}-\pi_{\mathrm{k}, \mathrm{i}}^{\mathrm{S}} \cdot \mathrm{P}_{\mathrm{k}, \mathrm{i}}^{\mathrm{S}}+\mathcal{P d}_{\mathrm{k}, \mathrm{i}}\right) \\
\left(\mathrm{P}_{\mathrm{k}, \mathrm{i}}^{\mathrm{B}}-\mathrm{P}_{\mathrm{k}, \mathrm{i}}^{\mathrm{S}}\right)+\left(\mathrm{P}_{\mathrm{k}, \mathrm{i}}^{\mathrm{BC}}-\mathrm{P}_{\mathrm{k}, \mathrm{i}}^{\mathrm{BD}}\right)=\left(\mathrm{P}_{\mathrm{k}, \mathrm{i}}^{\mathrm{Ld}}-\mathrm{P}_{\mathrm{k}, \mathrm{i}}^{\mathrm{DG}}\right) \\
0 \leq \mathrm{P}_{\mathrm{k}, \mathrm{i}}^{\mathrm{BD}} \leq \min \left(\mathrm{P}_{\mathrm{k}, \mathrm{i}, \max }^{\mathrm{BD}}, \mathrm{P}_{\max }^{\mathrm{BD}}\right) \\
0 \leq \mathrm{P}_{\mathrm{k}, \mathrm{i}}^{\mathrm{BC}} \leq \min \left(\mathrm{P}_{\mathrm{k}, \mathrm{i}, \max }^{\mathrm{C}}, \mathrm{P}_{\max }^{\mathrm{BC}}\right) \\
E_{\mathrm{k}, \mathrm{i}}=E_{\mathrm{k}, i-1}+\eta_{C, k, i} \mathrm{P}_{\mathrm{k}, \mathrm{i}}^{\mathrm{BC}}-\frac{\mathrm{P}_{\mathrm{k}, \mathrm{i}}^{\mathrm{BD}}}{\eta_{D, k, i}} \\
E_{\min } \leq E_{\mathrm{k}, \mathrm{i}} \leq \mathrm{E}_{\max , \mathrm{k}, \mathrm{i}}
\end{gathered}
$$

Now, the equality given in (4) [36] is used to combine problem (1) and (3) into a single problem and by using auxiliary variables $u_{\mathrm{k}, \mathrm{i}}^{B D}$ and $u_{\mathrm{k}, \mathrm{i}}^{B C}$ for the scenario $k$ in the hour $i$, such as $u_{\mathrm{k}, \mathrm{i}}^{B D}=\min \left(\mathrm{P}_{\mathrm{k}, \mathrm{i}, \text { max }}^{\mathrm{BD}}, \mathrm{P}_{\max }^{\mathrm{BD}}\right)$ and $u_{\mathrm{k}, \mathrm{i}}^{B C}=\min \left(\mathrm{P}_{\mathrm{k}, \mathrm{i}, \max }^{\mathrm{BC}}, \mathrm{P}_{\max }^{\mathrm{BC}}\right)$, the proposed problem is solved as a single stage stochastic LP given as:

$$
\inf _{\mathrm{x}}\left(\mathrm{f}(\mathrm{x})+\sup _{\mathrm{y}}(\mathrm{g}(\mathrm{x}, \mathrm{y}))\right)=\inf _{\mathrm{x}, \mathrm{y}}(\mathrm{f}(\mathrm{x})+\mathrm{g}(\mathrm{x}, \mathrm{y}))
$$

The problem can now be written as:

$$
\begin{aligned}
& \text { Min } p_{i n} \cdot \mathrm{E}_{\max }+\sum_{\mathrm{k}=1}^{\mathrm{K}} \gamma_{\mathrm{k}} \sum_{\mathrm{i}=1}^{T}\left(\pi_{\mathrm{k}, \mathrm{i}}^{\mathrm{B}} \cdot \mathrm{P}_{\mathrm{k}, \mathrm{i}}^{\mathrm{B}}-\pi_{\mathrm{k}, \mathrm{i}}^{\mathrm{S}} \cdot \mathrm{P}_{\mathrm{k}, \mathrm{i}}^{\mathrm{S}}+\mathcal{P} \mathrm{d}_{\mathrm{k}, \mathrm{i}}\right) \\
& 0 \leq \mathrm{E}_{\max } \leq \mathrm{E}_{p} \\
& \left(\mathrm{P}_{\mathrm{k}, \mathrm{i}}^{\mathrm{B}}-\mathrm{P}_{\mathrm{k}, \mathrm{i}}^{\mathrm{S}}\right)+\left(\mathrm{P}_{\mathrm{k}, \mathrm{i}}^{\mathrm{BC}}-\mathrm{P}_{\mathrm{k}, \mathrm{i}}^{\mathrm{BD}}\right)=\left(\mathrm{P}_{\mathrm{k}, \mathrm{i}}^{\mathrm{Ld}}-\mathrm{P}_{\mathrm{k}, \mathrm{i}}^{\mathrm{DG}}\right) \\
& 0 \leq \mathrm{P}_{\mathrm{k}, \mathrm{i}}^{\mathrm{BD}} \leq u_{\mathrm{k}, \mathrm{i}}^{B D} \\
& 0 \leq \mathrm{P}_{\mathrm{k}, \mathrm{i}}^{\mathrm{BC}} \leq u_{\mathrm{k}, \mathrm{i}}^{B C} \\
& E_{\mathrm{k}, \mathrm{i}}=E_{\mathrm{k}, i-1}+\eta_{C, k, i} \mathrm{P}_{\mathrm{k}, \mathrm{i}}^{\mathrm{BC}}-\frac{\mathrm{P}_{\mathrm{k}, \mathrm{i}}^{\mathrm{BD}}}{\eta_{D, k, i}} \\
& E_{\min } \leq E_{\mathrm{k}, \mathrm{i}} \leq \mathrm{E}_{\max , \mathrm{k}, \mathrm{i}}
\end{aligned}
$$

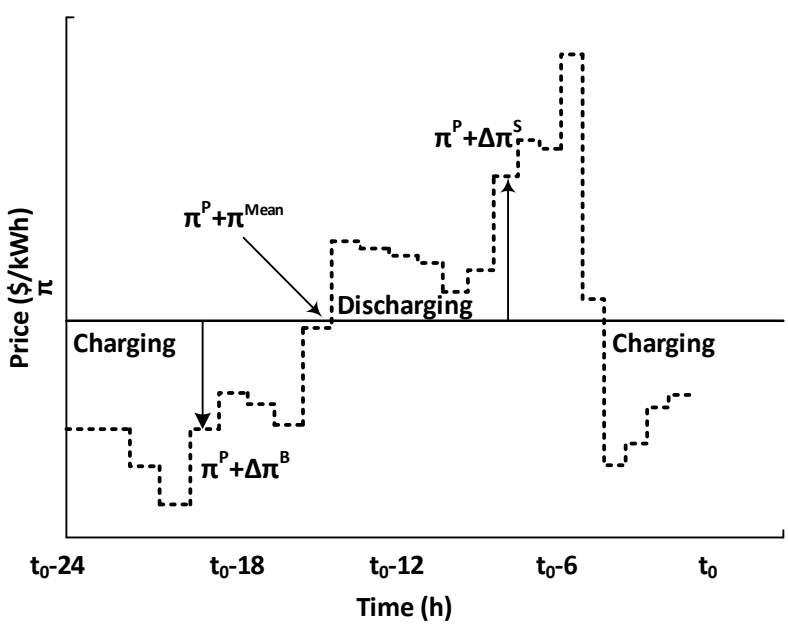

Fig. 2. An illustration of the marginal electricity market price for a timeperiod $T$. The charging area indicates that the price is inexpensive such that the price is below the shifted mean price $\pi^{P}+\pi^{\text {Mean }}$, while the discharging area shows that the price is expensive such that the price is above the shifted mean price $\pi^{P}+\pi^{\text {Mean }}$

\section{B. Energy Storage Operation based on the Marginal Price}

Since the economic gain of the BESS depends on the diurnal pattern of the daily price profile. The strategy is simple: the energy storage is charged when the price is low and discharged when the price is high. Nowadays, negative market price peaks are becoming common due to the rising renewable energy penetration into the power grid. Therefore, to enable the proposed approach to work successfully under such conditions, price profile shifting property is utilized. Regardless of the values of the price profiles, a big positive shift $\pi^{\mathrm{P}}$ is added, so that, even in case of negative peaks, the price profile shifts to the positive region. The shifted mean price $\pi^{\mathrm{P}}+\pi^{\text {Mean }}$ is calculated as the average of the shifted forecast price profile of $T$ hours (24-hours) in future to set a reference, against which the shifted hourly prices can be compared and classified as expensive or inexpensive as shown in Fig. 2. Now, for calculating how much the BESS should be charged or discharged, it is important to determine how often the current hour price will be more or will be less expensive than the mean price. This serves as a base for the derivation of the chargingdischarging power ratings and efficiencies of the BESS.

\section{Energy Storage Efficiency}

In many papers, the efficiency losses, the charging power limit and the discharging power limit are taken as constants. However, many researchers have identified the fact that this approach is inaccurate and can produce misleading optimization results [37]-[39]. Therefore, in this paper, the efficiency losses are modelled as a function of $I^{2} R$ losses as the charging power and the discharging power varies and consequently, based on the derived efficiency losses the charging and discharging power limits are determined.

The flow of the energy through the BESS is shown by the circuit diagram shown in Fig. 3 [40]. As shown in the circuit, the stored energy during the charging of BESS for scenario $k$ in the ith hour is given as:

$$
\Delta E_{\text {int }}=\eta_{C, k, i} \cdot \mathrm{P}_{\mathrm{k}, \mathrm{i}}^{\mathrm{BC}} \cdot \Delta t
$$




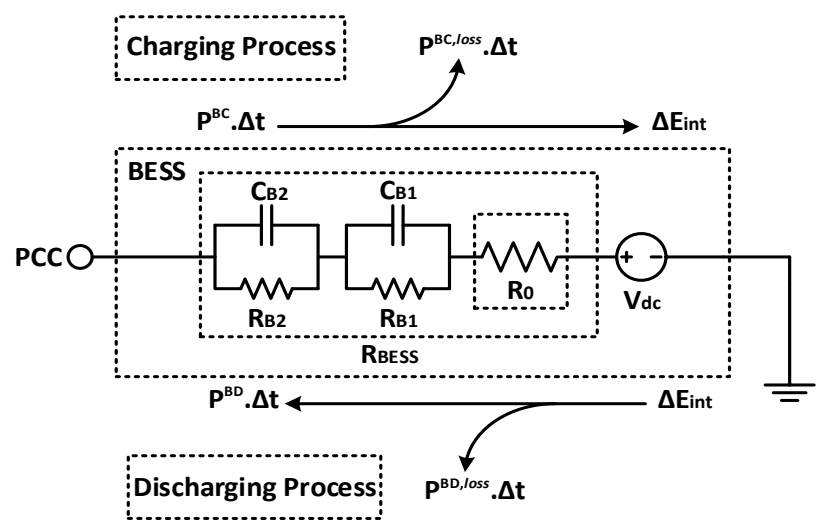

Fig. 3. The flow of energy through the BESS (Expressed through BESS model), where $V_{d c}$ represents the internal dc voltage and $R_{B E S S}$ denotes the resistance between the point of connection with the distribution network and the internal source considering $V_{d c}$ base [40].

Where $\Delta t$ is the time step taken as an hour in this paper. Similarly, the energy taken out from the BESS during the discharging for scenario $k$ in the $i t h$ hour is given as:

$$
\Delta E_{\text {int }}=\frac{\mathrm{P}_{\mathrm{k}, \mathrm{i}}^{\mathrm{BD}}}{\eta_{D, k, i}} \cdot \Delta t
$$

To have a profitable trade for the BESS in a given time step, for the scenario $k$ in the ith hour, the energy value during discharging must be greater than the energy value when the charging takes place such as:

$$
\mathrm{P}_{\mathrm{k}, \mathrm{i}}^{\mathrm{BD}} \cdot \Delta t \cdot\left(\pi^{\mathrm{P}}+\pi_{\mathrm{k}, \mathrm{i}}^{\mathrm{S}}\right)>\mathrm{P}_{\mathrm{k}, \mathrm{i}}^{\mathrm{BC}} \cdot \Delta t \cdot\left(\pi^{\mathrm{P}}+\pi_{\mathrm{k}, \mathrm{i}}^{\mathrm{B}}\right)
$$

It is important to note that (8) is not a hard constraint, but a desired condition for the profitable operation.

By rearranging (6) and (7) for a round-trip charging of BESS's internal energy $\Delta E_{\text {int }}$, and substituting into (8), we obtain:

$$
\begin{gathered}
\Delta E_{\text {int }} \cdot \eta_{D, k, i} \cdot\left(\pi^{\mathrm{P}}+\pi_{\mathrm{k}, \mathrm{i}}^{\mathrm{S}}\right)>\frac{\Delta E_{\text {int }}}{\eta_{C, k, i}} \cdot\left(\pi^{\mathrm{P}}+\pi_{\mathrm{k}, \mathrm{i}}^{\mathrm{B}}\right) \\
\frac{\left(\pi^{\mathrm{P}}+\pi_{\mathrm{k}, \mathrm{i}}^{\mathrm{S}}\right)}{\left(\pi^{\mathrm{P}}+\pi_{\mathrm{k}, \mathrm{i}}^{\mathrm{B}}\right)}>\frac{1}{\eta_{C, k, i} \cdot \eta_{D, k, i}}
\end{gathered}
$$

It means that the ratio of the energy-selling price (when discharging) to the energy buying price (when charging) for every scenario $k$ in an hour $i$ must be greater than the inverse of the round-trip efficiency for a profitable trade.

In order to model inherently, the mutual exclusiveness of charging and discharging modes for every scenario $k$ in an hour $i$, the charging and discharging conditions given in (10) are modified to incorporate the mean price term such that:

$$
\frac{\left(\pi^{\mathrm{P}}+\pi_{\mathrm{k}, \mathrm{i}}^{\mathrm{S}}\right)}{\pi^{\mathrm{P}}+\pi^{\mathrm{Mean}}} \cdot \frac{\pi^{\mathrm{P}}+\pi^{\text {Mean }}}{\left(\pi^{\mathrm{P}}+\pi_{\mathrm{k}, \mathrm{i}}^{\mathrm{B}}\right)}>\frac{1}{\eta_{C, k, i}} \cdot \frac{1}{\eta_{D, k, i}}
$$

Such that:

$$
\left(\pi^{\mathrm{P}}+\pi_{\mathrm{k}, \mathrm{i}}^{\mathrm{B}}\right) \leq \pi^{\mathrm{P}}+\pi^{\text {Mean }} \leq\left(\pi^{\mathrm{P}}+\pi_{\mathrm{k}, \mathrm{i}}^{\mathrm{S}}\right)
$$

Independently, for charging and discharging modes respectively, it can be written as:

$$
\begin{aligned}
& \frac{\pi^{\mathrm{P}}+\pi^{\text {Mean }}}{\left(\pi^{\mathrm{P}}+\pi_{\mathrm{k}, \mathrm{i}}^{\mathrm{B}}\right)}>\frac{1}{\eta_{C, k, i}} \\
& \frac{\left(\pi^{\mathrm{P}}+\pi_{\mathrm{k}, \mathrm{i}}^{\mathrm{S}}\right)}{\pi^{\mathrm{P}}+\pi^{\text {Mean }}}>\frac{1}{\eta_{D, k, i}}
\end{aligned}
$$

Note that, the variables $\left(\pi^{\mathrm{P}}+\pi^{\text {Mean }}\right),\left(\pi^{\mathrm{P}}+\pi_{\mathrm{k}, \mathrm{i}}^{\mathrm{B}}\right),\left(\pi^{\mathrm{P}}+\right.$ $\left.\pi_{\mathrm{k}, \mathrm{i}}^{\mathrm{S}}\right), \eta_{C, k, i}$ and $\eta_{D, k, i}$ are positive, and both the conditions in
(13) and (14) are true, then (11) can be satisfied and thus (10) is also satisfied. This strategy allows the independent calculations of the BESS's charging and discharging power limits on the basis of corresponding efficiencies. The price $\pi_{\mathrm{k}}^{\text {Mean }}$ is selected arbitrarily, although here it is chosen as the mean price from the 24-hour time period for the scenario $k$. This duration is such that it covers the diurnal patterns of the price profiles.

If the efficiencies associated with the BESS are to be taken as constant, (13) and (14) would suffice for determining the charging and discharging decisions on the basis of round-trip efficiency and energy price. However, in this paper, BESS efficiencies are modeled as a function of charging and discharging powers, in terms of the corresponding $I^{2} R$ losses. The efficiency during charging for the scenario $k$ in hour $i$ can be given as:

$$
\eta_{C, k, i}\left(\mathrm{P}_{\mathrm{k}, \mathrm{i}}^{\mathrm{BC}}\right)=\frac{\mathrm{P}_{\text {out }}}{\mathrm{P}_{\mathrm{in}}}=\frac{\mathrm{P}_{\mathrm{k}, \mathrm{i}}^{\mathrm{BC}}-\mathrm{P}_{\mathrm{k}, \mathrm{i}}^{\mathrm{BC} \text { loss }}}{\mathrm{P}_{\mathrm{k}, \mathrm{i}}^{\mathrm{BC}}}
$$

Where the charging losses $\mathrm{I}_{\mathrm{BESS}, \mathrm{BC}}^{2} \cdot \mathrm{R}_{\mathrm{BESS}}$ are given as:

$\mathrm{P}_{\mathrm{k}, \mathrm{i}}^{\mathrm{BC} \text { loss }}=\left(\frac{\mathrm{P}_{\mathrm{k}, \mathrm{i}}^{\mathrm{BC}}}{V_{d c}}\right)^{2} \cdot\left(\mathrm{R}_{0}+\frac{\mathrm{R}_{\mathrm{B} 1} \mathrm{X}_{\mathrm{CB} 1}}{\mathrm{R}_{\mathrm{B} 1}+\mathrm{X}_{\mathrm{CB} 1}}+\frac{\mathrm{R}_{\mathrm{B} 2} \mathrm{X}_{\mathrm{CB} 2}}{\mathrm{R}_{\mathrm{B} 2}+\mathrm{X}_{\mathrm{CB} 2}}\right) \cdot 10^{3}$

Where $\mathrm{R}_{\mathrm{BESS}} \approx \mathrm{R}_{0}+\mathrm{R}_{\mathrm{B} 1}+\mathrm{R}_{\mathrm{B} 2}$, The scaling factor of $10^{3}$ is used to ensure that all the values are in kilowatts. By substituting (16) into (15):

$$
\eta_{C, k, i}\left(\mathrm{P}_{\mathrm{k}, \mathrm{i}}^{\mathrm{BC}}\right)=1-\mathrm{P}_{\mathrm{k}, \mathrm{i}}^{\mathrm{BC}}\left(\frac{\mathrm{R}_{\mathrm{BESS}} \cdot 10^{3}}{\mathrm{~V}_{\mathrm{dc}}^{2}}\right)
$$

Similarly, the efficiency during discharging for the scenario $k$ in hour $i$ can be given as:

$$
\eta_{D, k, i}\left(\mathrm{P}_{\mathrm{k}, \mathrm{i}}^{\mathrm{BD}}\right)=\frac{\mathrm{P}_{\text {out }}}{\mathrm{P}_{\text {in }}}=\frac{\mathrm{P}_{\mathrm{k}, \mathrm{i}}^{\mathrm{BD}}}{\mathrm{P}_{\mathrm{k}, \mathrm{i}}^{\mathrm{BD}}+\mathrm{P}_{\mathrm{k}, \mathrm{i}}^{\mathrm{BD} \text { loss }}}
$$

Where the discharging losses $\mathrm{I}_{\mathrm{BESS}, \mathrm{BD}}^{2} \cdot \mathrm{R}_{\mathrm{BESS}}$ are given as:

$$
\mathrm{P}_{\mathrm{k}, \mathrm{i}}^{\mathrm{BD} \text { loss }}=\left(\frac{\mathrm{P}_{\mathrm{k}, \mathrm{i}}^{\mathrm{BD}}}{\mathrm{V}_{\mathrm{dc}}}\right)^{2} \cdot\left(\mathrm{R}_{0}+\frac{\mathrm{R}_{\mathrm{B} 1} \mathrm{X}_{\mathrm{CB} 1}}{\mathrm{R}_{\mathrm{B} 1}+\mathrm{X}_{\mathrm{CB} 1}}+\frac{\mathrm{R}_{\mathrm{B} 2} \mathrm{X}_{\mathrm{CB} 2}}{\mathrm{R}_{\mathrm{B} 2}+\mathrm{X}_{\mathrm{CB} 2}}\right) \cdot 10^{3}
$$
(18):

Where $\mathrm{R}_{\mathrm{BESS}} \approx \mathrm{R}_{0}+\mathrm{R}_{\mathrm{B} 1}+\mathrm{R}_{\mathrm{B} 2}$, By substituting (19) into

$$
\eta_{D, k, i}\left(\mathrm{P}_{\mathrm{k}, \mathrm{i}}^{\mathrm{BD}}\right)=\frac{1}{1+\mathrm{P}_{\mathrm{k}, \mathrm{i}}^{\mathrm{BD}}\left(\frac{\mathrm{R}_{\mathrm{BESS}} \cdot 10^{3}}{\mathrm{~V}_{\mathrm{dc}}^{2}}\right)}
$$

\section{Energy Storage Charging and Discharging Power Limits}

The charging power limit of the BESS for the scenario $k$ in hour $i$ is derived on the basis of the efficiency losses by substituting (17) into (13) such that:

$$
\frac{\pi^{\mathrm{P}}+\pi_{\mathrm{k}}^{\text {Mean }}}{\pi^{\mathrm{P}}+\pi_{\mathrm{k}, \mathrm{i}}^{\mathrm{B}}}>\frac{1}{1-\mathrm{P}_{\mathrm{k}, \mathrm{i}}^{\mathrm{BC}}\left(\frac{R_{B E S S} \cdot 10^{3}}{V_{d c}^{2}}\right)}
$$

This inequality in (21) is changed to equality because, this is taken as upper bound to the charging power in scenario $k$ at hour $i$ such that:

$$
\mathrm{P}_{\mathrm{k}, \mathrm{i}, \text { max }}^{\mathrm{BC}}=\left(1-\frac{\pi^{\mathrm{P}}+\pi_{\mathrm{k}, \mathrm{i}}^{\mathrm{B}}}{\pi^{\mathrm{P}}+\pi_{\mathrm{k}}^{\mathrm{Mean}}}\right) \cdot\left(\frac{V_{d c}^{2}}{R_{B E S S} \cdot 10^{3}}\right)
$$

The second term in (22) represents the maximum charging power, that can be limited to the BESSs charging limit $\mathrm{P}_{\max }^{\mathrm{BC}}$. Like the charging power limit, the discharging power limit can be obtained by substituting (20) into (14) such that: 


$$
\frac{\pi^{\mathrm{P}}+\pi_{\mathrm{k}, \mathrm{i}}^{\mathrm{S}}}{\pi^{\mathrm{P}}+\pi_{\mathrm{k}}^{\text {Mean }}}>1+\mathrm{P}_{\mathrm{k}, \mathrm{i}}^{\mathrm{BD}}\left(\frac{R_{\text {BESS }} \cdot 10^{3}}{V_{d c}^{2}}\right)
$$

Similarly, the inequality in (23) is transformed into equality by setting the upper bound of the discharging power in scenario $k$ at hour $i$ such that:

$$
\mathrm{P}_{\mathrm{k}, \mathrm{i}, \max }^{\mathrm{BD}}=\left(\frac{\pi^{\mathrm{P}}+\pi_{\mathrm{k}, \mathrm{i}}^{\mathrm{S}}}{\pi^{\mathrm{P}}+\pi_{\mathrm{k}}^{\text {Mean }}}-1\right) \cdot\left(\frac{V_{d c}^{2}}{R_{\text {BESS }} \cdot 10^{3}}\right)
$$

The second term in (24) represents the maximum charging power, that can be limited to the BESSs discharging limit $P_{\max }^{B D}$. The parameters of the BESS model used in the linear functions (17) and (20) during optimization process are derived experimentally in [40], which depicts the real behavior of BESS, therefore the loss of optimality seems really low.

\section{E. Energy Storage Capacity Fading}

The capacity fading in a BESS is the decrease in the amount of charge that an energy storage can deliver at the rated voltage with the increase in use (discharging cycles). The $\mathrm{SoC}$ is estimated using the Coulombs method. The capacity fading [41] for the scenario $k$ in hour $i$ can be incorporated in (5), such that:

$$
\lambda_{c, k, i}=1-b_{1} \sqrt{N_{k, i}}
$$

Where $\lambda_{c, k, i}$ is the multiplier for the nominal BESS capacity, $b_{1}$ is the fading coefficient and $N$ is the number of discharge cycles completed, that can be calculated as:

$$
N_{k, i}=N_{0}+\frac{1}{\mathrm{E}_{\max }} \cdot\left(\mathrm{P}_{\mathrm{k}, \mathrm{i}}^{\mathrm{BD}} \cdot \Delta t\right)
$$

Where $N_{0}$ is the pre simulation number of completed discharge cycles. The capacity limits can be updated, such that:

$$
\mathrm{E}_{\max , \mathrm{k}, \mathrm{i}}=\lambda_{c, k, i} . \mathrm{E}_{\max }
$$

Although, the capacity fading is not significant for a single day but over the life span of the BESS, it becomes significant. Therefore, it is incorporated at the second stage of the energy management approach by scaling the first stage optimum capacity by $\lambda_{c, k, i}$.

\section{F. Stochastic Price, Solar PV Power and Load Scenarios}

To generate the scenarios for the price, solar PV power and load demand, the following procedure is applied:

\section{1) Forecasting Model:}

The statistical seasonal auto-regressive integrated moving average (SARIMA) model is used to generate the random time series on the basis of historical data [42].

\section{2) Distribution Transformation:}

The time series generated by the SARIMA model is in terms of a white noise and follows the normal distribution. However, the actual solar PV radiation follows Beta distribution. Therefore, in case of such a parameter, the distribution transformation procedure is used to transform the generated time series into a new series that follows their respective distribution. In this procedure, first the cumulative probability distribution function (CDF) of the time series generated by SARIMA model is calculated, which provides the probability of occurrence of each scenario, that are assigned as the weights of these scenarios in the stochastic process. For these probabilities, the inverse of a new specific distribution CDF is calculated for generating the actual scenarios [43]. The price and load demand follows the standard Gaussian distribution.
3) Parameter Conversion:

The parameters for solar power based on the solar radiation, require conversion from the radiation profile to the generated power based on the installed solar power plants physical parameters [43].

\section{4) Scenario Reduction:}

To reduce the computational burden, a very large set of generated scenarios are reduced appropriately without losing the stochastic properties significantly. In the proposed approach, the scenario-reduction algorithm reduces and bundles the scenarios using the Kantorovich distance matrix [44]. The probability of all the deleted scenarios is assumed zero, while the new probabilities of the preserved scenarios are equal to the sum of their former probabilities and the probabilities of the deleted scenarios that are closest to them.

\section{RESULTS AND DISCUSSIONS}

In this section, the data sets obtained from two different industrial units in the New South Wales (NSW), Australia as shown in Fig. 1, industry-1 and industry-2 microgrids are employed to evaluate the performance of the proposed energy management strategy.

\section{A. Data description}

The proposed energy management strategy is applied to the real data from the two different types of industries, i.e., an industry with pumping station and an IT and business center. The industrial load demands are quite different from the residential load demands. Therefore, the SARIMA forecasting method is applied to the real data and the forecast is calculated. A typical forecasted scenario of the two industrial microgrids for the load demands and the solar power profile are shown in Fig. 4 and Fig. 5 respectively. In addition, a typical locational marginal price profile for the above microgrids is shown in Fig. 6 . The rated capacities of the solar power plants installed at industry- 1 and industry- 2 are $50 \mathrm{~kW}$ and $250 \mathrm{~kW}$ respectively. As shown in Fig. 4, the load demand of industry-1 is highly abrupt and has sharp spikes that is entirely different from the generated solar power profile. Therefore, a BESS must be installed to utilize the generated solar power and to supply the load demands efficiently.

Similarly, Fig. 5 shows the load demand and solar power generation profile for the industry-2, the load demand reflects the working hours of the industry. However, the generated solar power is not enough to supply the load; therefore, a BESS is needed to fulfill the requirement.

\section{B. Implementation of the Proposed Energy Management Strategy}

The proposed energy management strategy is implemented in Matlab ${ }^{\circledR}$ to optimize the operational cost of the microgrid with the scalability of the BESS in the four different case studies based on the real data of two industrial microgrids.

The investment cost is $1000 \$ / \mathrm{kWh}$ for the BESS and the model parameters given in Table I are taken from [40]. Also, the DC source value is $48 \mathrm{~V}$. The life span is assumed to be 15 years [45]. It is to be noted that the payback period is calculated by dividing the expected initial investment of the BESS by the annualized expected profit. Moreover, the daily operation cost is calculated as the difference of the total power bought and sold to the grid plus daily peak demand charges (daily peak demand charges $\times \max \left(\mathrm{P}_{\mathrm{i}}^{\mathrm{B}}\right)$ ), which is further determined for the whole 


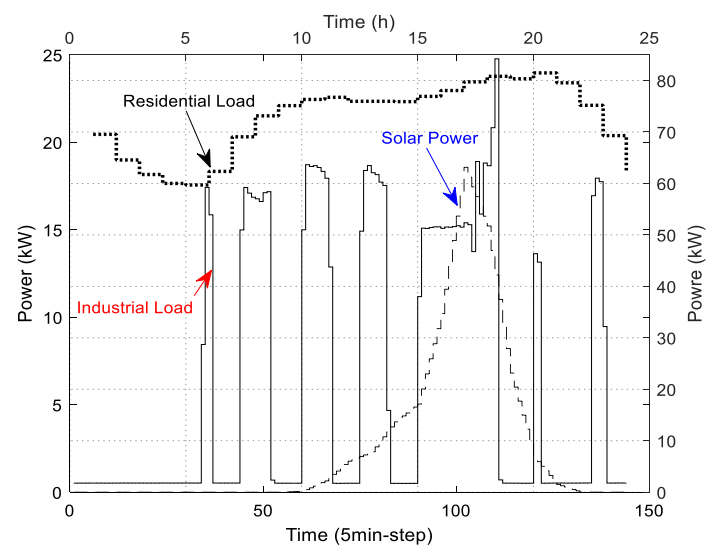

Fig. 4. A typical forecasted scenario obtained from the data set of industry-1

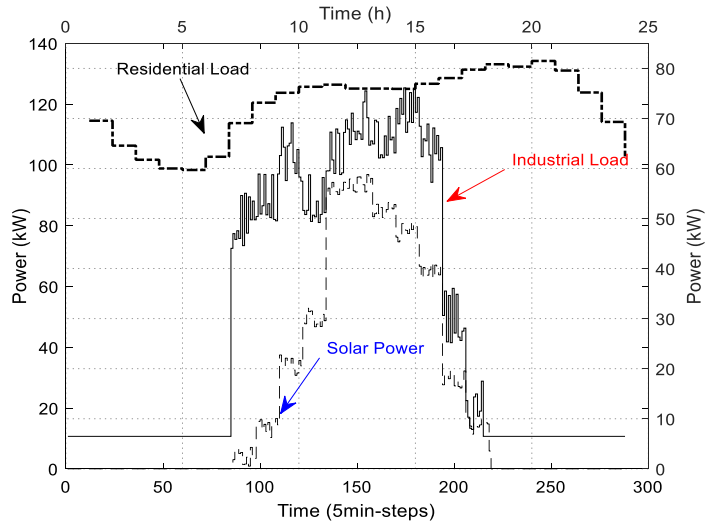

Fig. 5. A typical forecasted scenario obtained from the data set of industry-2

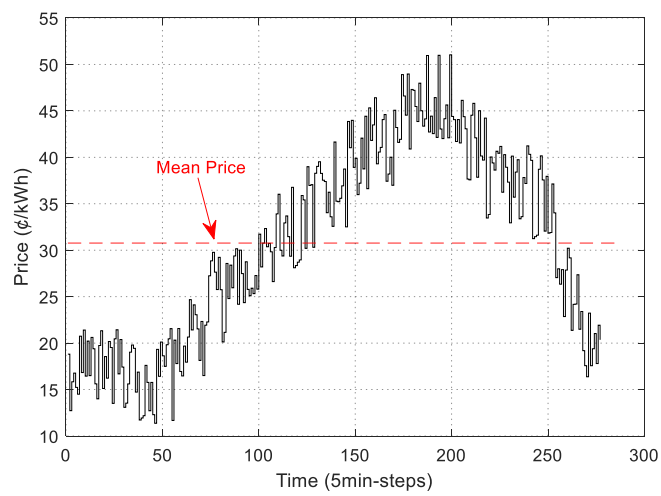

Fig. 6. A typical locational marginal price profile of electricity

TABLE I

LOOKUP TABLE FOR THE BESS MODEL PARAMETERS

\begin{tabular}{ccccccccc}
\hline \hline $\mathbf{E}(\boldsymbol{\%})$ & $\mathbf{2 0 - 3 0}$ & $\mathbf{3 0 - 4 0}$ & $\mathbf{4 0 - 5 0}$ & $\mathbf{5 0 - 6 0}$ & $\mathbf{6 0 - 7 0}$ & $\mathbf{7 0 - 8 0}$ & $\mathbf{8 0 - 9 0}$ & $\mathbf{9 0 - 1 0 0}$ \\
\hline \hline $\mathbf{R}_{\mathbf{0}}(\boldsymbol{\Omega})$ & 2.00 & 2.70 & 2.90 & 2.40 & 2.50 & 3.10 & 2.60 & 2.70 \\
\hline $\mathbf{R}_{\mathrm{B} 1}(\boldsymbol{\Omega})$ & 0.10 & 0.10 & 0.10 & 0.10 & 0.10 & 0.09 & 0.11 & 0.10 \\
\hline $\mathbf{R}_{\mathrm{B} 2}(\boldsymbol{\Omega})$ & 0.12 & 0.10 & 0.12 & 0.23 & 0.22 & 0.17 & 0.16 & 0.15
\end{tabular}

life span of BESS. The scaled BESS parameters given in Table I are selected from the look up table during the optimization based on the initial energy level of the BESS. The daily demand charge and the penalty factor are assumed as $30 \notin / \mathrm{kW}$ and $100 \notin / \mathrm{kW}$ respectively. The demand peak threshold parameter is taken as $100 \mathrm{~kW}$. The minimum BESS capacity limit is considered as $10 \%$ of the total capacity. In order to compensate for the real-time operation mismatch $10 \%$ of the BESS capacity is preserved at the day-ahead stage. The BESS fading coefficient is taken as $10^{-3}$ and the pre simulation number of completed discharge cycles are taken as 10 . The fixed charging and discharging efficiency of the BESS is $89 \%$. To model the

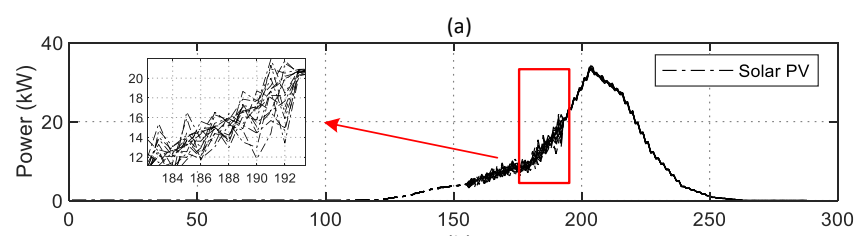

(b)
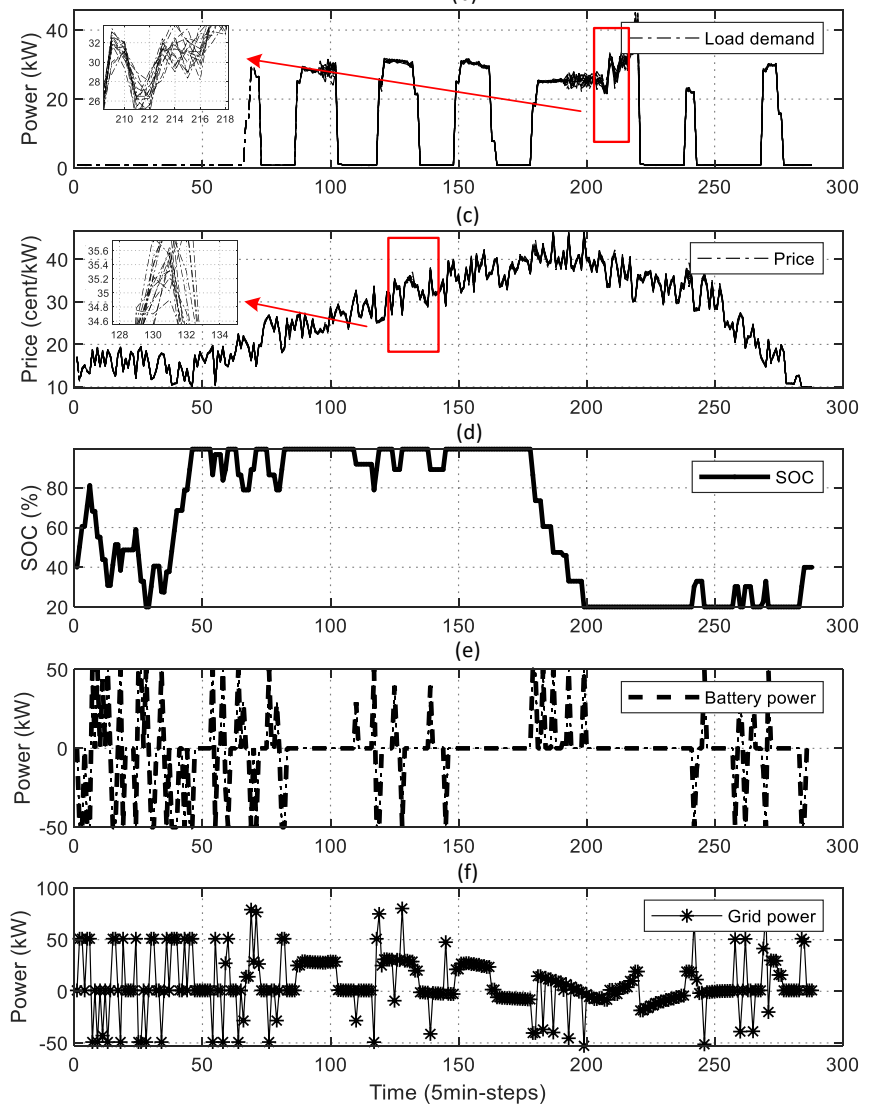

Fig. 7. Scenarios optimization process to determine the optimum operation of the BESS in industry-1 microgrid

load demand, solar generation and price uncertainties, 365 scenarios are generated using the method given in Section II-F, which are then reduced to a smaller subset, which can well approximate the original entire scenario for performing the simulation. The case studies are as follows:

\section{1) Case Study 1: Industry-1 Microgrid with Real Data}

Based on the set of the stochastic scenarios, the proposed optimization is performed for the industry-1 microgrid. The optimum size of the BESS obtained for this case is $42 \mathrm{kWh}$ as shown in Fig. 11 (a). To represent the uncertainty in the load, the solar PV and the price variation, the reduced set of scenarios are considered by adding the randomness to the deterministic profiles as shown in Fig. 7(a), 7(b) and 7(c) respectively. For each of these scenarios, the simulation is carried out to derive the optimum operation of BESS, thus a set of battery operation is obtained for all the given scenarios. From this set, a probability distribution of the BESS operation is established, and the optimum operation of the BESS is estimated as the one with the highest probability in that set given in the Fig. 7(d) and 7(e). Consequently, the calculate power interaction with the grid is shown in Fig. 7(f).

As shown in Fig. 7(a) and (b), the load profile and the solar PV output power experiences more variation during the early afternoon period since a small passing cloud can strongly 

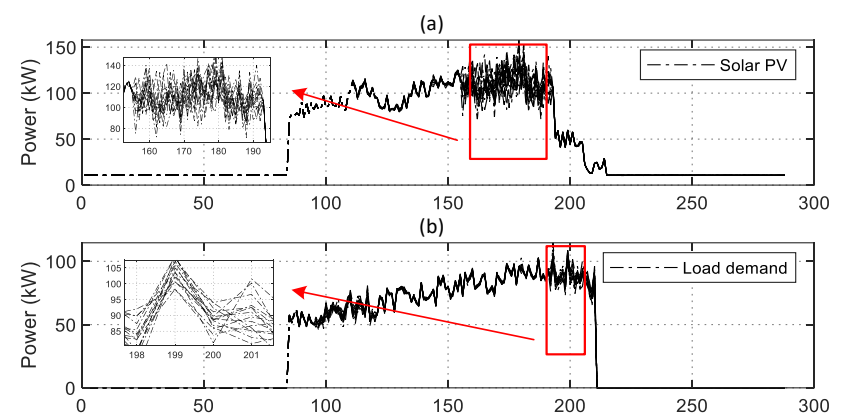

(c)
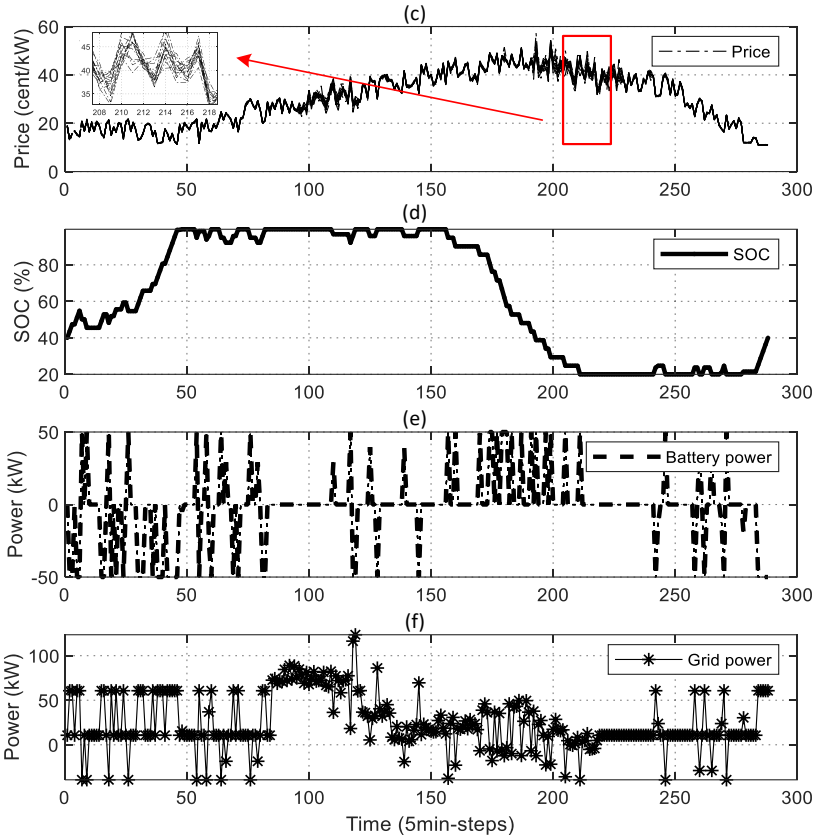

Fig. 8. Scenarios optimization process to determine the optimum operation of the BESS in industry-2 microgrid

influence the amount of the irradiance reaching to the PV surface. These variations in the load and the solar PV lead to various scenarios of possible PV operations, which form a spectrum of operation. Fig. 7(a) and 7(b) shows that these scenarios follow a trend, and the mean value of the central line can be considered as the optimum typical operation of the battery. Looking at the battery power variation closely, the battery charges in the early morning when the price is low, and it may do further charging when the solar PV output is greater than the load in the early afternoon. In the early morning, the electricity price is low, so the battery is charging from $0 \mathrm{am}$ to about $7 \mathrm{am}$. In this period, the SoC value increases to its maximum value to about $100 \%$. After $7 \mathrm{am}$, the price increases, so the battery does not charge anymore. Since the solar PV output is not sufficient to supply the local load, the microgrid still import the power from the main grid to supply the local load since the price is still low. From around $1 \mathrm{pm}$ to $3 \mathrm{pm}$, the PV output surpasses the load, so the microgrid exports the excess power to the main grid. After $3 \mathrm{pm}$, the price is high, and the PV output is not sufficient for the local load, so the battery discharges to supply partially the load until its SoC reach its minimum level at about $8 \mathrm{pm}$. After that, the price reduces, so the battery is ready to be charged again to prepare for the next day discharge. The results are given in Table II.

The operational cost for this case is $\$ 1,38,880$ and the corresponding investment cost resulted to be $\$ 42,000$ for the whole life span of BESS. While, the annual profit is calculated
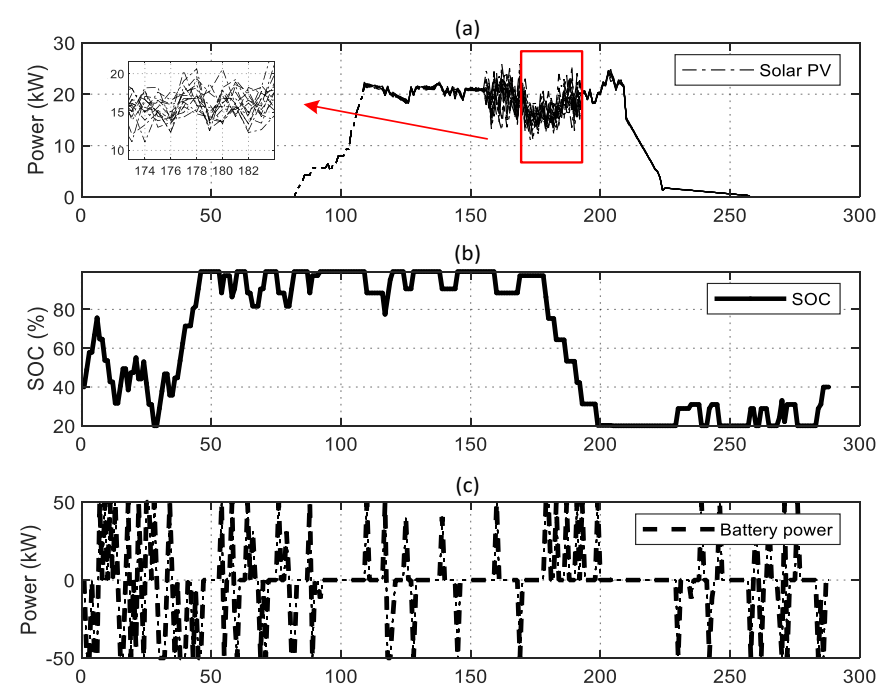

(d)

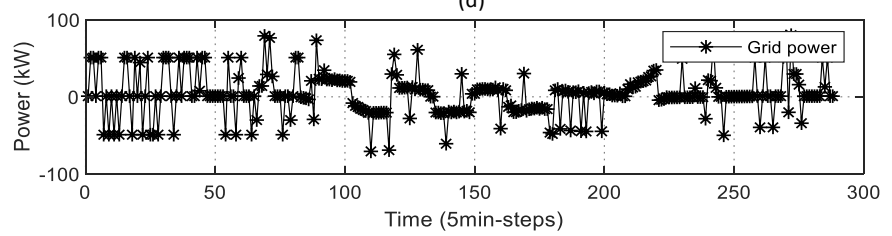

Fig. 9. Scenarios optimization process results of the optimum operation of the BESS in industry-1 microgrid with solar PV in both morning and afternoon

as $\$ 4,159.7$. So, the payback period is calculated as 10.09 years.

\section{2) Case Study 2: Industry-2 Microgrid with Real Data}

The optimum size of the BESS obtained in this case is 170 kWh as shown in Fig. 11(c). Fig. 8(a) shows that the uncertainty of the load is higher in the working hours from 8 am to $5 \mathrm{pm}$, and this can be explained by the working hours of the industry. The uncertainty is included in the load demand, PV output and price by considering the stochastic scenarios as shown in Fig. $8(a)$, (b) and (c) respectively.

The results are given in Table II. The operational cost is $\$ 7,53,660$ and the investment cost is $\$ 1,70,000$ for the complete life span of BESS. While, the annual profit is calculated as $\$ 15,275$. Therefore, the payback period for this case is 11.12 years. The simulation results show that the proposed strategy effectively calculates the optimum size of the BESS and successfully reduces the microgrid operational cost, while addressing all the uncertainties involved in the decision process.

\section{3) Case Study 3: Industry-1 Microgrid with Solar PV Power in both Morning and Afternoon}

In this case, the solar profile for the industry-1 is slightly varied such that the solar PV power generation is available in both in the morning and the afternoon as shown in Fig. 9(a). The optimum size of the BESS obtained in this case is $42 \mathrm{kWh}$. The results are summarized in Table III. The operational cost is $\$ 7,030$ and the investment cost is $\$ 42,000$ for the complete life span of BESS. While, the annual profit is calculated as $\$ 4,159.70$. Therefore, the payback period for this case is 10.09 years. The results show that due to higher availability of solar PV power the operational cost is reduced significantly, while the annual profit has been increased. Moreover, the proposed approach efficiently calculated the microgrid operation as shown in Fig. 9(b), (c) and (d). 
TABLE II

SuMMARY OF RESUlTS IN CASE STUDIES 1 AND 2

\begin{tabular}{|c|c|c|c|c|}
\hline Results & $\begin{array}{c}\text { Case study } 1 \text { with } \\
\text { proposed approach }\end{array}$ & $\begin{array}{c}\text { Case study } 1 \text { with fixed } \\
\text { BESS parameters }\end{array}$ & $\begin{array}{l}\text { Case study } 2 \text { with } \\
\text { proposed approach }\end{array}$ & $\begin{array}{c}\text { Case study } 2 \text { with fixed } \\
\text { BESS parameters }\end{array}$ \\
\hline Operational cost without BESS (\$) & $2,01,280.00$ & $2,01,280.00$ & $9,82,792.79$ & $9,82,792.79$ \\
\hline Operational cost with BESS (\$) & $1,38,880.00$ & $1,48,740.00$ & $7,53,660.00$ & $8,83,890.00$ \\
\hline Investment cost $(\$)$ & $42,000.00$ & $36,000.00$ & $1,70,000.00$ & $80,000.00$ \\
\hline Annual profit (\$) & $4,159.70$ & $3,502.87$ & $15,275.00$ & $6,593.86$ \\
\hline Payback period (years) & 10.09 & 10.27 & 11.12 & 12.13 \\
\hline Optimum capacity of BESS ( $k W h)$ & 42.00 & 36.00 & 170.00 & 80.00 \\
\hline
\end{tabular}

TABLE III

SUMMARY OF RESUlTS IN CASE STUdies 3 AND 4

\begin{tabular}{lcc}
\hline \multicolumn{1}{c}{ Results with proposed approach } & Case study $\mathbf{3}$ & Case study 4 \\
\hline \hline Operational cost without BESS $\mathbf{( \$ )}$ & $1,01,483.53$ & $36,450.91$ \\
\hline Operational cost with BESS $\mathbf{( \$ )}$ & $7,030.00$ & 316.89 \\
\hline Investment cost $\mathbf{\$}$ ) & $42,000.00$ & $1,02,000.00$ \\
\hline Annual profit $\mathbf{\$}$ ) & $4,159.70$ & $23,556.00$ \\
\hline Payback period (years) & 10.09 & 4.33 \\
\hline Optimum capacity of BESS (kWh) & 42.00 & 102.00 \\
\hline \hline
\end{tabular}

4) Case Study 4: Industry-1 Microgrid with Solar PV Power in both Morning and Afternoon and Negative Price Peaks

In this case, with the same solar profile for the industry- 1 as in case study 3 , a price profile with negative price peaks as shown in Fig. 10(a) is simulated. The optimum size of the BESS obtained in this case is $102 \mathrm{kWh}$. The results are summarized in Table III. The operational cost is $\$ 316.89$, and the investment cost is $\$ 102,000$ for the complete life span of BESS. While, the annual profit is calculated as $\$ 23,556$. Therefore, the payback period for this case is 4.33 years. As shown in Fig. 10(b), the proposed approach benefits from the negative price peak and charges the BESS, which is followed by a positive price discharge and therefore gains higher profits. Consequently, the payback period decreases. Moreover, the power flow of the BESS and the grid are also shown in Fig. 10(c) and Fig. 10(d).

C. Improvement of Energy Management with variable Energy Storage Parameters in Comparison to Fixed Parameters

The proposed energy management strategy is implemented using both proposed and fixed BESS parameters where the proposed variable parameters resulted in significant improvement. As shown in Fig. 11, in case of the proposed parameters, the optimum capacity for industry-1 microgrid increases by an amount of $6 \mathrm{kWh}$ and in the case of industry- 2 microgrid it increases by $90 \mathrm{kWh}$. Hence, the operational costs for the lifespan of BESS for the industry-1 and industry-2 microgrids decreases by $\$ 9,860$ and $\$ 1,30,230$ respectively. Furthermore, the decrease in the operational cost increases the profit and hence decreases the payback time for the investment. Therefore, the proposed strategy is efficient.

\section{CONCLUSION}

In this paper, an integrated energy management strategy is proposed that aims to optimize the operation of the industrial microgrid subject to the scalability of the BESS. The proposed two-stage energy management strategy is formulated as a single stage LP and solved efficiently. The inherent uncertainties in the load demand, renewable generation and price are incorporated into the optimization model through the stochastic scenario generations. The proposed strategy is evaluated based on the data sets obtained from two different industrial units in NSW, Australia. The industrial data sets show that the load is highly sensitive and requires higher accuracy in the operation.
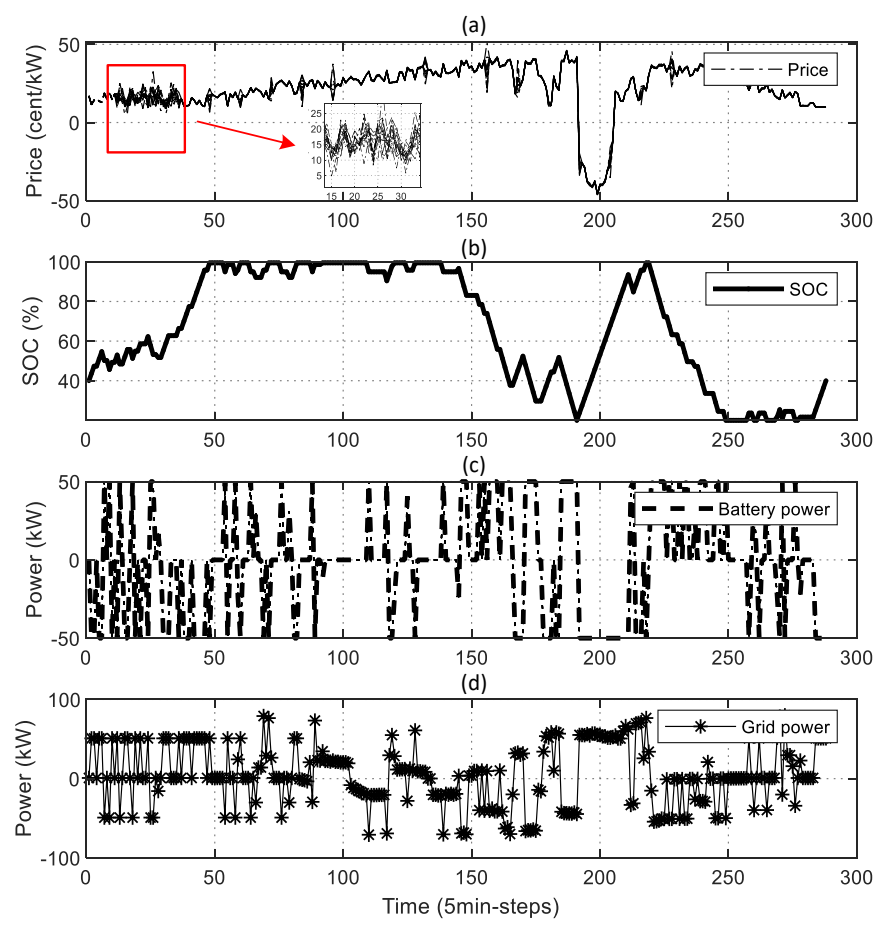

Fig. 10. Scenarios optimization process results of the optimum operation of the BESS in industry-1 microgrid with solar PV in both morning and afternoon against a price profile with negative peaks
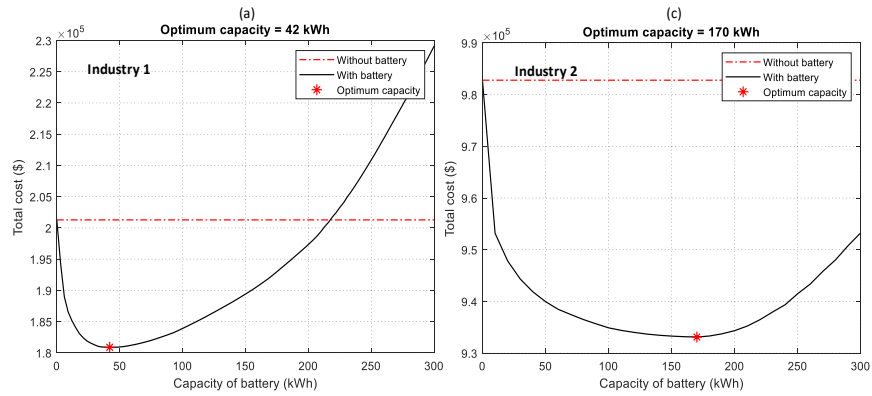

(b)
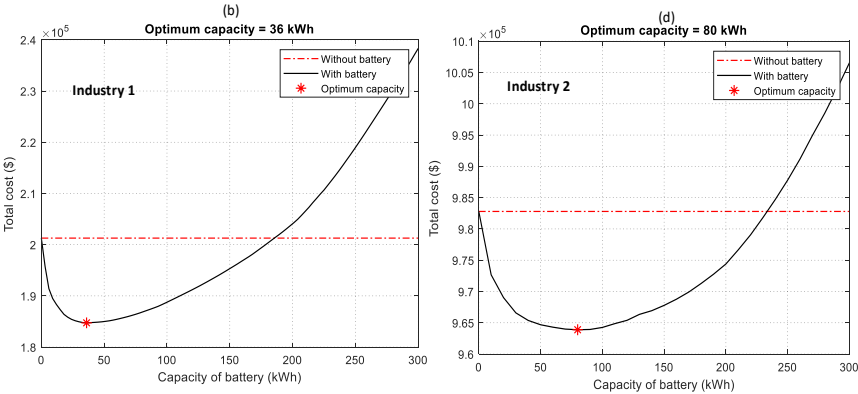

Fig. 11. Optimum capacity of the BESS: (a) Industry-1 microgrid by the proposed approach; (b) Industry-1 microgrid using fix BESS parameters; (c) Industry-2 microgrid by the proposed approach and (d) Industry-2 microgrid using fix BESS parameters 
Correspondingly, the results show that the proposed energy management strategy effectively calculates the size of BESS while minimizing the cost of operation for the industrial microgrid.

The contributions of this paper are as follows:

- This paper proposes a novel two-stage energy management strategy for the integrated BESS within the industrial microgrid when connected to the distribution network.

- This paper uses a novel and more accurate BESS model to assure a more accurate calculation of the BESS capacity.

- The proposed approach is successfully evaluated by the numerical studies based on real data.

Future work involves incorporating this formulation into a microgrid controller so that it can be used in an energy management with multiple distributed energy resources.

\section{REFERENCES}

[1] M. S. Illindala, H. J. Khasawneh, and A. A. Renjit, "Flexible distribution of energy and storage resources: Integrating these resources into a microgrid," IEEE Industry Applications Magazine, vol. 21, no. 5, pp. 32-42, 2015.

[2] M. A. Haj-ahmed and M. S. Illindala, "Investigation of Protection Schemes for Flexible Distribution of Energy and Storage Resources in an Industrial Microgrid," IEEE Transactions on Industry Applications, vol. 3, no. 51, pp. 2071-2080, 2015

[3] F. Wang et al., "Multi-objective optimization model of source-load-storage synergetic dispatch for a building energy management system based on TOU price demand response," IEEE Transactions on Industry Applications, vol. 54, no. 2, pp. 1017-1028, 2017.

[4] G. Mohy-ud-din, K. M. Muttaqi and D. Sutanto, "An Effective Power Dispatch Strategy to Improve Generation Schedulability by Mitigating Wind power Uncertainty with a Data Driven flexible Dispatch Margin for a Wind Farm using a Multi-Unit Battery Energy Storage System," 2018 IEEE Industry Applications Society Annual Meeting (IAS), Portland, OR, 2018, pp. 1-8.

[5] Y. Tian, A. Bera, M. Benidris, and J. Mitra, "Stacked revenue and technical benefits of a grid-connected energy storage system," IEEE Transactions on Industry Applications, vol. 54, no. 4, pp. 3034-3043, 2018.

[6] S. Mohagheghi and N. Raji, "Dynamic demand response: A solution for improved energy efficiency for industrial customers," IEEE Industry Applications Magazine, vol. 21, no. 2, pp. 54-62, 2014.

[7] Y. M. Ding, S. H. Hong, and X. H. Li, "A demand response energy management scheme for industrial facilities in smart grid," IEEE Transactions on Industrial Informatics, vol. 10, no. 4, pp. 2257-2269, 2014.

[8] A. Chaouachi, R. M. Kamel, R. Andoulsi, and K. Nagasaka, "Multiobjective intelligent energy management for a microgrid," IEEE Transactions on Industrial Electronics, vol. 60, no. 4, pp. 1688-1699, 2012.

[9] H. K. Nunna and S. Doolla, "Multiagent-based distributed-energy-resource management for intelligent microgrids," IEEE Transactions on Industrial Electronics, vol. 60, no. 4, pp. 1678-1687, 2012.

[10] P. M. van de Ven, N. Hegde, L. Massoulié, and T. Salonidis, "Optimal control of end-user energy storage," IEEE Transactions on Smart Grid, vol. 4, no. 2, pp. 789-797, 2013.

[11]C. A. Hill, M. C. Such, D. Chen, J. Gonzalez, and W. M. Grady, "Battery energy storage for enabling integration of distributed solar power generation," IEEE Transactions on smart grid, vol. 3, no. 2, pp. 850-857, 2012.

[12] I. Koutsopoulos, V. Hatzi, and L. Tassiulas, "Optimal energy storage control policies for the smart power grid," in 2011 IEEE International Conference on Smart Grid Communications (SmartGridComm), 2011, pp. 475-480: IEEE.

[13] M. Choobineh and S. Mohagheghi, "Robust Optimal Energy Pricing and Dispatch for a Multi-Microgrid Industrial Park Operating Based on Just-InTime Strategy," IEEE Transactions on Industry Applications, 2019.

[14] C. Zhang, Y. Xu, Z. Y. Dong, and L. Yang, "Multi-Timescale Coordinated Adaptive Robust Operation for Industrial Multi-Energy Micro-Grids with Load Allocation," IEEE Transactions on Industrial Informatics, 2019.

[15] M. Sepehry, M. H. Kapourchali, V. Aravinthan, and W. Jewell, "Robust DayAhead Operation Planning of Unbalanced Microgrids," IEEE Transactions on Industrial Informatics, 2019.

[16]F. Y. Melhem, O. Grunder, Z. Hammoudan, and N. Moubayed, "Energy Management in Electrical Smart Grid Environment Using Robust Optimization Algorithm," IEEE Transactions on Industry Applications, vol. 54, no. 3, pp. 2714-2726, 2018.

[17]Z. Shi, H. Liang, S. Huang, and V. Dinavahi, "Distributionally robust chanceconstrained energy management for islanded microgrids," IEEE Transactions on Smart Grid, vol. 10, no. 2, pp. 2234-2244, 2018.

[18] O. Ciftci, M. Mehrtash, and A. K. Marvasti, "Data-Driven Nonparametric Chance-Constrained Optimization for Microgrid Energy Management," IEEE Transactions on Industrial Informatics, 2019

[19] A. T. Eseye, D. Zheng, J. Zhang, and D. Wei, "Optimal energy management strategy for an isolated industrial microgrid using a modified particle swarm optimization," in 2016 IEEE International Conference on Power and Renewable Energy (ICPRE), 2016, pp. 494-498: IEEE.

[20] N. K. Paliwal, R. Mohanani, N. K. Singh, and A. K. Singh, "Demand side energy management in hybrid microgrid system using heuristic techniques," in 2016 IEEE International Conference on Industrial Technology (ICIT), 2016, pp. 1910-1915: IEEE

[21] H. Pandzic, Y. Wang, T. Qiu and D. S. Kirschen, "Nearoptimal method for siting and sizing of distributed storage in a transmission network," IEEE Trans. Power Syst., v 30, n 5, p 2288-2300, Sep. 2015.

[22] F. Garcia-Torres and C. Bordons, "Optimal economical schedule of hydrogen-based microgrids with hybrid storage using model predictive control," IEEE Transactions on Industrial Electronics, vol. 62, no. 8, pp. 5195-5207, 2015.

[23] F. Garcia-Torres, C. Bordons, and M. A. Ridao, "Optimal economic schedule for a network of microgrids with hybrid energy storage system using distributed model predictive control," IEEE Transactions on Industrial Electronics, vol. 66, no. 3, pp. 1919-1929, 2018

[24] A. Saad, T. Youssef, A. T. ElSayed, A. Amin, O. H. Abdalla, and O. A. Mohammed, "Data-Centric Hierarchical Distributed Model Predictive Control for Smart Grid Energy Management," IEEE Transactions on Industrial Informatics, 2018.

[25] J. R. Birge and F. Louveaux, Introduction to stochastic programming. Springer Science \& Business Media, 2011.

[26] H. Farzin, M. Fotuhi-Firuzabad, and M. Moeini-Aghtaie, "Stochastic energy management of microgrids during unscheduled islanding period," IEEE Transactions on Industrial Informatics, vol. 13, no. 3, pp. 1079-1087, 2016.

[27] D. Lee, J. Kim, and R. Baldick, "Stochastic optimal control of the storage system to limit ramp rates of wind power output," IEEE Transactions on Smart Grid, vol. 4, no. 4, pp. 2256-2265, 2013.

[28] Y. Ji, J. Wang, S. Yan, W. Gao, and H. Li, "Optimal microgrid energy management integrating intermittent renewable energy and stochastic load," in 2015 IEEE Advanced Information Technology, Electronic and Automation Control Conference (IAEAC), 2015, pp. 334-338: IEEE.

[29] X. Xi, R. Sioshansi, and V. Marano, "A stochastic dynamic programming model for co-optimization of distributed energy storage," Energy Systems, vol. 5, no. 3, pp. 475-505, 2014.

[30]S. Talari, M. Yazdaninejad, and M.-R. Haghifam, "Stochastic-based scheduling of the microgrid operation including wind turbines, photovoltaic cells, energy storages and responsive loads," IET Generation, Transmission \& Distribution, vol. 9, no. 12, pp. 1498-1509, 2015.

[31] Z. Zhou, J. Zhang, P. Liu, Z. Li, M. C. Georgiadis, and E. N. Pistikopoulos, "A two-stage stochastic programming model for the optimal design of distributed energy systems," Applied Energy, vol. 103, pp. 135-144, 2013.

[32]B. Moradzadeh and K. Tomsovic, "Two-stage residential energy management considering network operational constraints," IEEE Transactions on Smart Grid, vol. 4, no. 4, pp. 2339-2346, 2013.

[33]S. Ahmed, "Two-Stage Stochastic Integer Programming: A Brief Introduction," Wiley Encyclopedia of Operations Research and Management Science, 2010.

[34]J. R. Birge, "Decomposition and partitioning methods for multistage stochastic linear programs," Oper. Res., vol. 33, no. 5, pp. 989-1007, 1985.

[35] G. Mohy-ud-din, D. H. Vu, K. M. Muttaqi and D. Sutanto, " An Integrated Energy Management Approach for the Economic Operation of Industrial Microgrids under Uncertainty of Renewable Energy," 2019 IEEE Industry Applications Society Annual Meeting (IAS), Baltimore, MD, 2019, pp. 1-8.

[36] S. Boyd and L. Vandenberghe, Convex Optimization. Cambridge, U.K.: Cambridge Univ. Press, 2004.

[37] C. M. Colson, M. H. Nehrir, R. K. Sharma, and B. Asghari, "Improving sustainability of hybrid energy systems part I: Incorporating battery roundtrip efficiency and operational cost factors," IEEE Trans. Sustain. Energy, vol. 5, no. 1, pp. 37-45, Jan. 2014.

[38] H. Karami, M. J. Sanjari, S. H. Hosseinian, and G. B. Gharehpetian, "An optimal dispatch algorithm for managing residential distributed energy resources," IEEE Trans. Smart Grid, vol. 5, no. 5, 2360-2367, Sep. 2014.

[39] C. M. Colson, M. H. Nehrir, R. K. Sharma, and B. Asghari, "Improving sustainability of hybrid energy systems part II: Managing multiple objectives with a multiagent system," IEEE Trans. Sustain. Energy, vol. 5, no. 1, pp. 4654, Jan. 2014.

[40] Kaveh Sarrafan, K. M. Muttaqi and D. Sutanto, "Real-time State-of-charge Tracking System Using Mixed Estimation Algorithm for Electric Vehicle Battery System." In 2018 IEEE Industry Applications Society Annual Meeting (IAS), pp. 1-8. IEEE, 2018

[41] P. Ramadass, B. Haran, R. White, and B. N. Popov, "Mathematical modeling of the capacity fade of Li-ion cells," Journal of Power Sources, vol. 123, no. 2, pp. 230-240, 2003

[42] D. J. Pedregal, J. Contreras, and A. A. S. de la Nieta, "ECOTOOL: a general MATLAB forecasting toolbox with applications to electricity markets," in Handbook of networks in power systems I: Springer, 2012, pp. 151-171.

[43] K. Zou, G. Mohy-Ud-Din, A. P. Agalgaonkar, K. M. Muttaqi, and S. Perera, "Distribution System Restoration with Renewable Resources for Reliability Improvement under System Uncertainties," IEEE Transactions on Industrial Electronics, pp. 1-1, 2019.

[44] K. C. Sharma, R. Bhakar, H. Tiwari, and S. Chawda, "Scenario based uncertainty modeling of electricity market prices," in 2017 6th International Conference on Computer Applications In Electrical Engineering-Recent Advances (CERA), 2017, pp. 164-168: IEEE.

[45] The Hornsdale Power Reserve of Australia [Online]. Available: https://hornsdalepowerreserve.com.au/faqs/ 


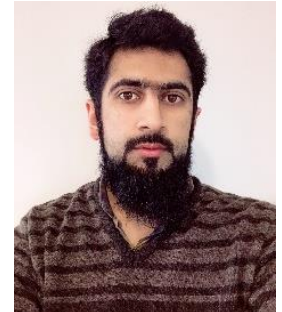

G. Mohy-ud-din (S'17) received the B.Sc. and M.Sc. degrees in Electrical Engineering from the University of Engineering and Technology, Taxila, Pakistan, in 2013 and 2015, respectively. He is currently working toward the Ph.D. degree in Electrical Engineering with the School of Electrical, Computer, and Telecommunications Engineering, University of Wollongong, Wollongong, NSW, Australia.

He has been a Lecturer in Electrical Engineering with COMSATS University, Islamabad, Pakistan, since 2016. He is a Research Student with the Australian Power Quality and Reliability Centre, University of Wollongong. His current research interests include the planning and operation of distributed energy resources, including renewable energy resources and energy storage.

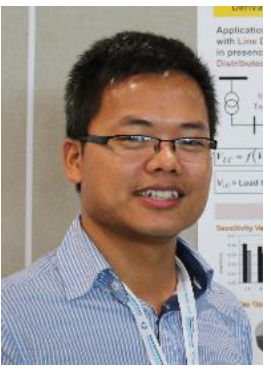

D. H. Vu received the B.E. (Electrical Engineering) and M.S. (Electrical Engineering) degrees from Hanoi University of Science and Technology, Hanoi, Vietnam in 2009 and 2011, respectively, and the Ph.D. degree in Electrical Engineering from University of Wollongong, Australia, in 2017. From July 2013 to December 2018, he was a part-time teaching staff at the School of Electrical, Computer, and Telecommunications Engineering, University of Wollongong. He is a peer reviewer for IEEE Trans on Power System, IEEE Trans on Industrial Application. Currently, he is a Power Sytem Engineer at Aurecon, Australia. His research interests include planning and operational aspects of renewable generation, electricity markets and power system stability.

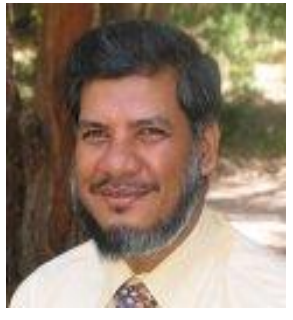

K. M. Muttaqi (M'01, SM'05) received the B.Sc. degree in electrical and electronic engineering from Bangladesh University of Engineering and Technology, Dhaka, Bangladesh in 1993, the M.Eng.Sc. degree in electrical engineering from University of Malaya, Kuala Lumpur, Malaysia in 1996 and the Ph.D. degree in Electrical Engineering from Multimedia University, Selangor, Malaysia in 2001. Currently, he is a Professor at the School of Electrical, Computer, and Telecommunications Engineering, and member of Australian Power Quality and Reliability Centre at the University of Wollongong, Wollongong, Australia. He was associated with the University of Tasmania, Hobart, Australia as a Research Fellow/Lecturer/Senior Lecturer from 2002 to 2007, and with the Queensland University of Technology, Brisbane, Australia as a Research Fellow from 2000 to 2002. Previously, he also worked for Multimedia University as a Lecturer for three years. He has more than 21 years of academic experience and authored or coauthored 300 papers in international journals and conference proceedings. His research interests include distributed generation, renewable energy, electrical vehicles, smart-grid, power system planning and emergency control.

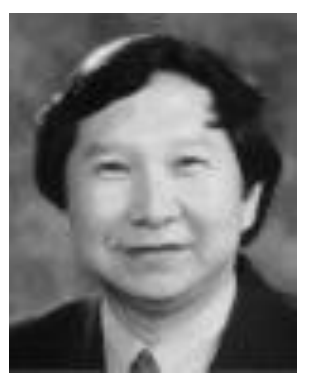

D. Sutanto (SM'89) obtained his BEng. (Hons) and $\mathrm{PhD}$ from the University of Western Australia in 1878 and 1981 respectively. He joined the University of New South Wales and later Hong Kong Polytechnic University where he was the Professor of Electrical Engineering. $\mathrm{He}$ is presently the Professor of Power Engineering at the University of Wollongong, Australia. His research interests include power system planning, analysis and harmonics, distributed generation, smart grid and Battery Energy Storage systems. He was the IEEE IAS Region 10 Area Chair from 2011-2017. He has published more than 450 papers with over 60 papers in refereed international journals. 